\section{artelogie}

\section{Artelogie}

Recherche sur les arts, le patrimoine et la littérature de l'Amérique latine

$12 \mid 2018$

Idiosyncrasie de l'indigénisme en Amérique latine.

Pluralité des sources et des appropriations extra-

latino-américaines

\title{
Indígenas de la nación. Etnografía histórica de la alteridad en México (Milpa Alta, siglos XVII- XXI), LÓPEZ Caballero Paula, 2017, México: FCE.
}

\section{Anahí Luna}

\section{OpenEdition}

Journals

Edición electrónica

URL: http://journals.openedition.org/artelogie/1761

DOI: 10.4000/artelogie.1761

ISSN: 2115-6395

Editor

Association ESCAL

\section{Referencia electrónica}

Anahí Luna, «Indígenas de la nación. Etnografía histórica de la alteridad en México (Milpa Alta, siglos XVIIXXI), LÓPEZ Caballero Paula, 2017, México: FCE. », Artelogie [En ligne], 12 | 2018, mis en ligne le 05 septembre 2018, consulté le 24 septembre 2020. URL : http://journals.openedition.org/artelogie/1761 ; DOI : https://doi.org/10.4000/artelogie.1761

Este documento fue generado automáticamente el 24 septembre 2020.

Association ESCAL 


\title{
Indígenas de la nación. Etnografía histórica de la alteridad en México (Milpa Alta, siglos XVII- XXI), LÓPEZ Caballero Paula, 2017, México: FCE.
}

\author{
Anahí Luna
}

1 A lo largo del libro, la antropóloga e historiadora mexicana Paula López Caballero aborda una crítica al esencialismo históricamente construido en torno a la categoría de lo indígena. Su análisis metodológico retoma tanto los procesos históricos como las relaciones de poder que han configurado esta categoría y con ello, busca develar los mecanismos con los cuales el Estado y sus poblaciones reconocidas como "singulares" han interactuado durante períodos prolongados. Configurado como una etnografía histórica de la alteridad, este estudio se fundamenta en dos hipótesis: la primera reconoce que no es el origen de las personas lo que determina las relaciones sociales, sino por el contrario, son las relaciones sociales las que determinan qué y quién es indígena. La segunda hipótesis, aborda esta autoctonía o sentido de origen como un fenómeno social indisociable del fenómeno estatal.

2 Esta publicación es una versión ampliada y modificada de la publicada en francés en 2012 (LÓPEZ: 2012). La investigación -realizada en un período de 10 años- parte de un acercamiento histórico y etnográfico de Milpa Alta, una de las 16 demarcaciones territoriales que conforman la Ciudad de México. Ubicada al sudoriente de la capital mexicana, la delegación Milpa Alta está conformada por 12 pueblos, mismos que en la actualidad gozan del reconocimiento oficial como pueblos originarios, ya sea por su permanencia y en su caso- resistencia- independiente al desarrollo de la Ciudad de México desde tiempos de la conquista y por poseer, entre otros, toponimias y Títulos primordiales que datan de la colonia. A diferencia de otros pueblos originarios de la Ciudad de México, Milpa Alta concentra la mayor proporción de nahua hablantes de la capital cuya ascendencia indígena- remarca la autora- es fuertemente reconocida y reivindicada. Aunado a ello, la historiadora demuestra cómo los propios pobladores han 
contribuido a construir un marco histórico que reconoce el control ininterrumpido que han tenido de estas tierras dese el siglo XII. En nuestros tiempos, el suelo que comprende Milpa Alta, se encuentra amenazado por el crecimiento demográfico desmedido de la urbe y la tala ilegal de sus bosques.

3 El estudio está dividido en dos partes. La primera, aborda aspectos históricos sobre la constitución del territorio en Milpa Alta desde el siglo XVI cuando ésta se convierte en una "cabecera de doctrina" que provee de servicios religiosos a los pueblos que rodean el lago de Xochimilco. Si bien, desde un inicio existen algunos conflictos en relación a la propiedad de las tierras, es hasta entrado el siglo XVII cuando la lucha por la posesión de un manantial desata un conflicto agrario sostenido durante tres siglos con el pueblo vecino de San Salvador Cuauhtenco. A la par de las pruebas presentadas por la población durante esta etapa temprana del conflicto, la autora repara en la relevancia del Título primordial como un conjunto de relatos orales que al exponer "una visión positiva del proceso de evangelización" contribuyen a "reforzar la legitimidad sobre el territorio". La correspondencia entre el régimen colonial de derecho y el sistema religioso y de patronazgo en el pueblo, constituyen un tipo particular de indigeneidad colonial que en el Centro de México, pareciera haberse desarrollado con relativa continuidad hasta inicios del siglo pasado, cuando la formación del Estado y su consecuente etapa posrevolucionaria provocarán "una ruptura del vínculo entre indigeneidad, territorio y religiosidad". Esta suerte de fractura, constitutiva de un sistema laicista dará pauta a la creación de nuevos relatos que trazan un arco de origen con el pasado prehispánico. Para la autora, la conformación de estas narrativas emanadas y subsidiadas por el Estado nación, abonarán las bases para la integración de este sector social hasta entonces marginado. Esta doble operación- sostiene- "creó un espacio simbólico en el que las poblaciones designadas como "diferentes" pudieron existir socialmente sin renunciar a su pertenencia nacional." Estas fuentes de originalidad que tanto la antropología como los artistas del régimen posrevolucionario buscaron en estas poblaciones sirvieron para delinear y construir rasgos de una mexicanidad que se leyó a través de la ideología del mestizaje y su brazo político: el indigenismo oficial. Esta corporación estatal operó con un objetivo en común: reformar y con ello, integrar a la alteridad en pro "de un discurso nacionalista que construyó su soberanía invocando la indigeneidad" y su consecuente patrimonialización como fenómenos vivos obligados a reproducir la tradición.

4 La segunda parte de libro analiza la operatividad de categorías de autoadscripción con las cuales los habitantes de Milpa Alta se han identificado como "indígenas" o en su caso "originarios". Ésta última- señala la autora- es una categoría con la cual ellos han respondido a la problemática llegada de nuevos habitantes a su territorio. El caso, resulta inquietante cuando son otros grupos de indígenas provenientes de Guerrero o de la Mixteca oaxaqueña los que se intentan insertar en su vida social. ¿Qué sucede- se pregunta- con la "legitimidad autóctona" que oponía hasta entonces a indígenas y no indígenas?, se trata pues, de un proceso de diferenciación interna, un efecto local del alterización manifestado a través de la dicotomía entre nativo/extranjero. El impacto que tendrá esta alteridad interna es relevante: mientras que los originarios conservarán su derecho a la tierra y a la filiación ancestral, los nuevos habitantes quedarán excluidos también de los cargos tradicionales que frente al Estado sustentan la indigeneidad de los pueblos. Resulta por tanto, interesante que este efecto local del alterización, pareciera replicar a la inversa, el proceso histórico que las poblaciones indígenas han tenido con el Estado mexicano. Es decir, la posición de alteridad es 
externa e interna a la vez, se mezcla, se rearticula y se trastoca a partir de relaciones de poder que no siempre están mediadas por el Estado. ¿Cómo- pregunta la antropólogaen medio de estos procesos se puede tener una existencia socialmente legítima como "otro" sin referirse al pasado patrimonializado ni tampoco ser un margen eventualmente absorbible? A mi parecer, una etnografía que nos hable de los procesos y las dinámicas internas de los pueblos que se han organizado políticamente en ausencia de la forma estatal podría enriquecer el debate sobre las formas de entender y trastocar eso que llamamos indigeneidad. A la sazón de esto, también resulta problemático considerar que esta "producción de alteridades ocurre siempre dentro de un campo de posibilidades ampliamente determinado por el Estado-nación". Desde otra aproximación crítica y metodológica, es posible ver cómo las posibilidades de conocimiento y experimentación de la otredad no siempre han estado mediadas por lo que ahora conocemos como Estado. El desafío, desde esta otra perspectiva nos obliga a articular prácticas y formas renovadas de coexistencia que no hacen converger las diferencias en una homogeneidad que implica otra forma de hegemonía. Es importante no olvidar que la condición de "indigeneidad" ha sido la mayor de las veces una imposición externa, promovida por el Estado y la antropología. Aunque ahora resulta una obviedad, este libro demuestra cómo la operatividad de la categoría históricamente constituida de "indígena" solamente se puede explicar en función de la existencia de un Estado. Si en la actualidad, existen grupos sociales que han empleado este esencialismo estratégico en el que se autoidentifican como "indígenas" es justamente porque han asumido que su uso también les garantiza una cierto respeto y reconocimiento a sus formas de vida. Por fortuna, en México y en el mundo, existen naciones y pueblos que han respondido de muy diversas formas a la simplificación de estas identidades colectivas demostrando así, que la lucha por el mantenimiento de la diferencia no está supeditada a la presencia del Estado.

\section{BIBLIOGRAFÍA}

Bibliografía:

LÓPEZ Caballero, Paula (2012), Les Indiens et la nation au Mexique: Une dimension

historique de l'altérité. Recherches internationales, Paris: Éditions Karthala.

LÓPEZ Caballero, Paula (2017), Indígenas de la nación. Etnografía histórica de la alteridad en México

(Milpa Alta, siglos XVII- XXI), México: FCE.

\section{AUTOR}

\section{ANAHÍ LUNA}

Université nationale autonome du Mexique (UNAM), Mexico 